\title{
Impact of neonatal intensive care
}

\author{
M H THOMPSON AND A S KHOT \\ Royal Alexandra Children's Hospital, Brighton
}

SUMmaRY Mortality in infants less than 33 weeks' gestation and in those of very low birthweight in Brighton has fallen since 1978. This reduction is not due simply to a decline in the incidence of major congenital abnormalities; evidence indicates that it can be attributed to the introduction of respiratory support.

Perinatal and neonatal mortality rates in Brighton have declined over the period $1972-82$ reflecting national trends. Recent advances in perinatal care are claimed to have greatly improved the survival rate of preterm and very low birthweight (less than $1500 \mathrm{~g}$ ) infants and regional neonatal intensive care units have been set up in many parts of the country. Demand for intensive care cots exceeds the supply, although controversy still exists over the value of neonatal intensive care ${ }^{12}$ and its effectiveness in the treatment of hyaline membrane disease. ${ }^{3}$

This paper documents the changes in perinatal mortality in Brighton between 1972 and 1982, and attempts to assess the influence of the introduction of neonatal intensive care, especially among very low birthweight infants.

\section{Method}

The Royal Sussex County Hospital is a district general hospital with a purpose built special care baby unit serving a population of approximately 300000 people. Neonatal intensive care has been practised increasingly since 1974 .

Data were derived from the annual perinatal statistics recorded by members of the paediatric staff and have been checked against the original records. All infants booked and delivered at the Royal Sussex County Hospital have been included, as have infants of mothers booked at the hospital but born before arrival. In utero and neonatal transfers from other hospitals have been excluded. Neonatal deaths include all babies born at or over 24 weeks' gestation who breathed and showed signs of life after delivery.

\section{Results}

Table 1 shows the perinatal and neonatal mortality
Table 1 Perinatal mortality rates for Brighton 1972-82 including percentage of low birthweight and preterm infants (figures in brackets are the rates after excluding infants with major congenital abnormalities)

\begin{tabular}{|c|c|c|c|c|c|}
\hline Year & $\begin{array}{l}\text { Perinatal } \\
\text { mortality } \\
\text { rate }\end{array}$ & $\begin{array}{l}\text { Neonatal } \\
\text { mortality } \\
\text { rates }\end{array}$ & Stillbirths & $\begin{array}{l}\text { Low birth- } \\
\text { weight } \\
\text { (\%) }\end{array}$ & $\begin{array}{l}\text { Preterm } \\
(\%)\end{array}$ \\
\hline 1972 & $20.8(16.4)$ & $11.4(9 \cdot 3)$ & $9.9(7.5)$ & $6 \cdot 5$ & $5 \cdot 2$ \\
\hline 1973 & $16.2(13.5)$ & $10 \cdot 2(8 \cdot 2)$ & $7 \cdot 1(5 \cdot 7)$ & $7 \cdot 3$ & $4 \cdot 4$ \\
\hline 1974 & $17.7(13.2)$ & $9 \cdot 1(4 \cdot 6)$ & $10.9(9 \cdot 0)$ & $7 \cdot 1$ & $5 \cdot 3$ \\
\hline 1975 & $19.2(14.5)$ & $11 \cdot 1(6 \cdot 9)$ & $9.8(7.0)$ & $7 \cdot 0$ & $5 \cdot 1$ \\
\hline 1976 & $20.1(13.7)$ & $11.8(6.9)$ & $10 \cdot 5(8 \cdot 5)$ & 4.9 & $4 \cdot 3$ \\
\hline 1977 & $18.6(12.5)$ & $11.4(9.0)$ & $9 \cdot 3(5 \cdot 3)$ & $5 \cdot 5$ & $5 \cdot 0$ \\
\hline 1978 & $13.8(10.2)$ & $10 \cdot 6(6 \cdot 6)$ & $5 \cdot 1(4 \cdot 0)$ & $5 \cdot 3$ & $4 \cdot 6$ \\
\hline 1979 & $10.9(9 \cdot 2)$ & $6.9(4.5)$ & $6 \cdot 1(5 \cdot 4)$ & $6 \cdot 6$ & $4 \cdot 4$ \\
\hline 1980 & $13.7(8.9)$ & $6.7(2.9)$ & $7 \cdot 3(5 \cdot 4)$ & $7 \cdot 0$ & $5 \cdot 2$ \\
\hline 1981 & $11.4(8.7)$ & $7.4(4.4)$ & $5 \cdot 3(4 \cdot 7)$ & $7 \cdot 7$ & $5 \cdot 4$ \\
\hline 1982 & $5 \cdot 7(5 \cdot 1)$ & $4.4(3.4)$ & $2 \cdot 7(2 \cdot 7)$ & $6 \cdot 6$ & $5 \cdot 6$ \\
\hline
\end{tabular}

rates for the Royal Sussex County Hospital, Brighton. The stillbirth, perinatal, and neonatal mortality rates have fallen since 1978 and the fall is still evident when deaths associated with major congenital abnormalities are excluded. The proportion of low birthweight and preterm infants has altered little over the period studied.

Table 2 shows the outcome since 1975 for preterm infants and those in the very low birthweight category, after excluding major congenital abnormalities. Mortality in infants under 33 weeks' gestational age and those of very low birthweight has decreased since 1978 . Respiratory support was introduced in 1974 and the proportion of very low birthweight infants receiving this altered little after 1976. Initially, few of the infants receiving respiratory support survived but the proportion surviving increased in the last few years of the study. There has been little alteration in survival in the infants not receiving respiratory support. 


\section{Thompson and Khot}

Table 2 Outcome for preterm infants and those of very low birthweight, Brighton 1975-82 (excluding major congenital abnormalities)

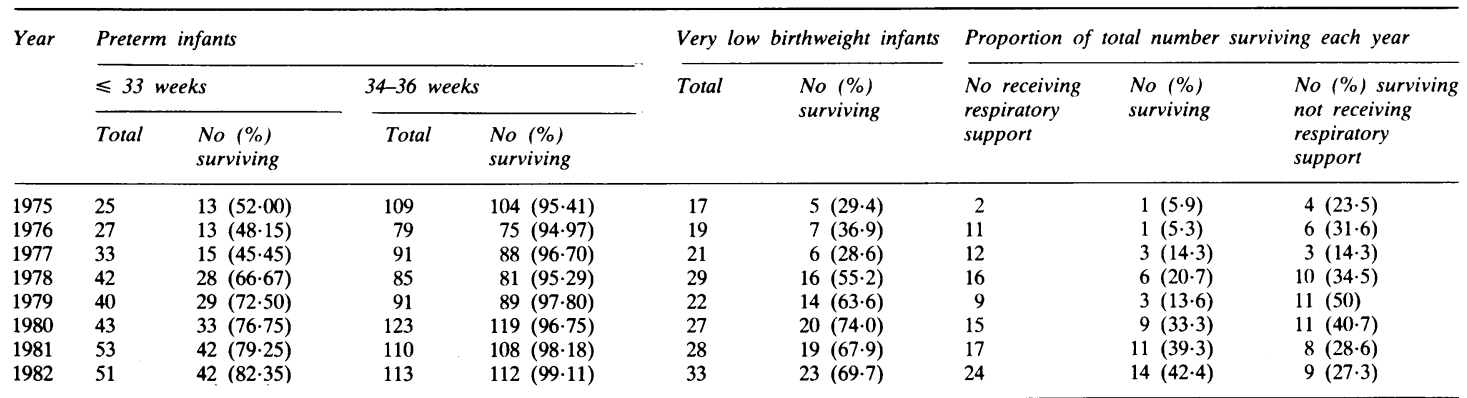

\section{Discussion}

It is difficult, in the absence of controlled trials, to show that intensive care reduces neonatal mortality, but our experience in Brighton suggests that its introduction has lowered neonatal mortality among very low birthweight infants. In the past decade the management of preterm infants has altered in several respects including fluid balance, feeding policies, temperature regulation, antibiotic prescription, and the use of respiratory support. Staff: patient ratios and the quality and quantity of equipment have also improved. Earlier studies ${ }^{12}{ }^{4}$ did not show that the introduction of neonatal intensive care was associated with an improvement in neonatal mortality in very low birthweight infants. A more recent study ${ }^{3}$ based on necropsy findings concluded that neonatal intensive care had been more successful in reducing deaths from birth asphyxia than those caused by respiratory distress. The prognosis, however, for outborn infants admitted to the same unit has been shown to be better than that of outborn infants declined admission. ${ }^{5}$

One of the most important recent changes in the management of the preterm baby has been the introduction of respiratory support which is most frequently given to the very low birthweight infant. Our results show there has been a fall in mortality among infants of less than 33 weeks' gestation and those in the very low birthweight category in Brighton since 1978. Respiratory support has been given to more than half the very low birthweight infants since 1976 and from 1978 onwards ventilation has been more successful. A proportion of very low birthweight infants survived before the introduction of respiratory support and our results indicate that this proportion has not altered. The overall improvement in the mortality in the very low birthweight group can therefore be attributed to effective respiratory support. There was no change in mean gestational age and birthweight in the very low birthweight group.

Survivors in the very low birthweight group are reported to have an incidence of handicap of around 6 to $8 \%,{ }^{6}$ and it is hoped that the developmental outcome of our very low birthweight survivors will be the subject of a further report.

We thank Dr Trevor Mann for initiating the Special Care Baby Unit and perinatal statistics in Brighton and all individuals and organisations who have helped support the unit over the years.

AK is supported by a grant from the Royal Alexandra Hospital Centenary Fund.

\section{References}

${ }^{1}$ Steiner ES, Sanders EM, Phillips ECK, Maddock CR. Very low birthweight children at school age: comparison of neonatal management methods. Br Med J 1980;281:1237-40.

2 Hughes-Davies TH. Conservative care of the newborn baby. Arch Dis Child 1979;54:59-61.

${ }^{3}$ Barson AJ, Tasker M, Lieberman BA, Hillier VF. Impact of improved perinatal care on the causes of death. Arch Dis Child 1984;59:199-207.

4 Jones RAK, Cummins M, Davies PA. Infants of very low birthweight. Lancet 1979;i:1332-5.

${ }^{5}$ Sims DG, Wynn J, Chiswick ML. Outcome of newborn babies declined admission to a regional neonatal intensive care unit. Arch Dis Child 1982;57:334-7.

6 Stewart AL, Reynolds EOR, Lipscomb AP. Outcome of infants of very low birthweight; survey of world literature. Lancet $1981 ; \mathbf{i}: 1038-41$.

Correspondence to $\operatorname{Dr} \mathrm{M} \mathrm{H}$ Thompson, Luton and Dunstable Hospital, Luton LU4 0DZ.

Received 22 October 1984 